\title{
The Reasoning for Methodical Instruments of Evaluation of Organization Readiness, Possibility and Necessity to Implement the Organizational Changes
}

\author{
Svetlana Igorevna Ashmarina \\ Anna Sergeevna Zotova
}

Samara State University of Economics, Russia, 443090, Samara, Sovetskoi Armii Street,141

Email: azotova@mail.ru

Doi:10.5901/mjss.2015.v6n3p44

Abstract

Organizational change implementation at the industrial enterprise is a complex task with multiple choice of decisions and with the demand to do a lot of preliminary work before starting the changes. On the basis of the empirical research about the specific characteristics of change implementation process and the existing approaches of assessment of enterprise readiness to changes the authors developed methodological instruments of integral assessment of organization readiness, possibility and necessity to implement the changes. The basic parameters of this assessment method were formed by the parameters of external environment comfort assessment, ability to implement the changes (staff resistance level), development potential level, level of changes implementation necessity. The object of the research is organizational and economic relationship appearing during change management process. The goal of the article is to offer the new assessment instrument for decision making process in change management.

Keywords: organization changes; change necessity; change implementation potential; development potential subsystems.

\section{Introduction}

\subsection{Background}

The basic principles of the external environment assessment were set out in the research works where the whole environment was divided into macro level environment systems and the micro level which can be influenced by the enterprise. (Porter M., 2004 ; Harrington H.J., 2006) The groups of organization stakeholders are usually formed from the system of microenvironment and they define the enterprise policy according to their own interests, so the matters of relationship of the enterprise and its stakeholders are also thoroughly studied. (Sokolova Y., 2013; Abrosimova E., Sedelnikov l., 2011)

To implement the organizational changes effectively it is necessary to do some preliminary work. The question of preliminary assessment of the possibility to implement the changes was recently studied and the suggested models are analyzing the possibility to implement the changes mostly from the point of view of staff readiness to them before starting the process of changes itself.(Weiner B.J., 2009; Khalitova I.,2013; Liden F., 2011;Lindgren M., 2012)

\subsection{Status of the problem}

The process of change management is rather complex and its fragmentary study, from the point of methods or main approaches does not allow to take into account system dynamics and synergy factors. This stipulated the objective need for concept approach to change management strategy in the organization. Authors' approach to the problem is more complex. As the basic criteria for substantiation of managerial decisions concerning change implementation we suggest: comfort level of external environment, ability of economic entities to implement the changes (the level of staff resistance), the potential of development of enterprise, the necessity to implement the changes. Rather important parameter should be the assessment of the enterprise potential for development which actually reflects the enterprise readiness for changes. But the greater role in our assessment methods is given to the change necessity assessment because rather often the reason for starting the changes is the groundless impression of company management about the urgency of changes. 


\section{Research Methodology}

Suggested authentic methodical instruments to assess the possibility, necessity and readiness of industrial enterprises to implement the changes is the result of the authors' research aimed to study specific factors that influence change implementation process. The assessment of any economic entity should be performed complexly and according to the system approach. It is sensible to evaluate the external environment and the enterprise itself as two interconnected systems. And the enterprise is only the part of more complex and multilevel external subsystem. The social system can be determined by complexity of interconnected social processes and events which are formed with the given target vector directed at the creation of the united unit.

So the suggested methodical instruments of assessment should be developed on the following principles:

1. Being based on the principle of system analysis of complex and multidimensional economic phenomena;

2. Contain the set of quantitative parameters of assessment in order to decrease the subjectivity;

3. Being defined by the set of unidirectional indicators which allow to have single-valued assessment; modeling.

The methods for the research are systems analysis, methods of expert judgments, economic and mathematical

\section{Findings}

\subsection{External environment comfort assessment}

External environment comfort determines the level of environment aptitude for effective functioning of the industrial enterprise. The environment can be comfortable when the activity of the enterprise is not restricted by the negative factors or limits and the uncomfortable environment is characterized by the great influence of the limits on the enterprise activity.

The research work has shown that the greatest influence on the level of organization readiness to changes was displayed by the following external systems: economic, political, social, ecological, technological, regional, sectoral and stakeholders' system.

In order to implement complex study of the environment influence level it was offered to use expert assessment. Each factor of external environment was assessed by the index which characterizes the quantity influence level. The best value of index was assessed by point "five", the worst - by point "one". The studied factors indexes should be differentiated according to the experts opinion to define their importance weight from "zero" to "one". Final assessment of each factor is a sum of the point of the factor multiplied to its weight. So we define the factors with the highest and the lowest indexes. The higher the influence index of the factor, the higher is the comfort level of the environment and the more effective will be change implementation.

The main factors influencing the enterprise readiness to implement the changes were studied and the most influential are the following:

- economic system - inflation speed; GDP per citizen; economy structure; quality of living and the living standards; tax system; investment attractiveness; innovation activity; the level of labour productivity; integration into global economy and others.

- political system - the level of political stability; legislation loyalty to entrepreneurial activity; existence of special economy development programs; legislative limits; the level of state support of business structures.

- $\quad$ social system - the level of demography; unemployment level; average level of wages; the level of retirement payments; life duration; education level; the level of medical services.

- regional system - GDP per citizen; the level of industrial production; demographic situation; regional attractiveness for investments; the level of population labour activity; financial stability of the region; the level of small-scale business development; the level of consumption.

- sectoral system - the volume and the structure of market demand; scientific and technology progress development; production intensification; development of progressive forms of social organization of production process; development of international links; the number of sectoral producers and others.

- stakeholders system - the number of stakeholders; their main characteristics; the level of their influence on the enterprise; the degree of personal interest of the enterprise in some stakeholders; the branching of stakeholders net. 


\subsection{Assessment of the enterprise ability to implement the changes.}

The greatest parameter that influences enterprise ability to implement the changes is staff resistance and the matter of this problem was thoroughly studied in the research works of of Ansoff (1990) who made a hypothesis about the possibility of staff resistance management with the help of various methods depending on the resistance degree and the time limits of change implementation. Also some methods of staff resistance assessment were suggested by Hiatt (2006). The main shortcomings of these research works are in absence of any practical ways or methods of assessment of staff resistance.

We define the main factors that influence staff resistance and divide them into three groups: technical, political, cultural. Technical factors are connected with influence of technical conditions at the enterprise. These conditions are mainly the ways of human and technical resources combination. The most important among them are: the level of communication infrastructure development (the factor influences information support of change implementation process); the isolation level in the enterprise; the level of purpose definiteness (the indefiniteness of future activities, the absence of its structuring into some stages according to the purposes may finally cause the appearance of the idea of unrealizable plans and unnecessary changes among the staff); the professional level of the leaders; the level of enterprise sustainability; the level of development of staff consulting and tutorial system.

Political factors are connected with redistribution of authority in case of structural and cultural changes in the enterprise. We suggest evaluating of the following ones: the level of authorities readiness to delegate responsibility; the level of management system flexibility; the level of management participation in making strategy decisions; the level of management system sensitivity to changes (influences the scale of changes possibilities and the managers readiness to implement the changes)

Cultural factors of change resistance are connected with values and social norms transformation: the level of former values influence; the norms control sustainability (as a rule the norms set for organizing enterprise activity may become a kind of dogmatic principles in organization development and any declination of them may cause the greater level of resistance); organization culture flexibility.

We have defined indexes for each group of factors, they give the complex assessment of highlighted research trends.

\subsection{Assessment of the enterprise potential to implement the changes and changes necessity.}

The importance of such assessment is defined by the necessity to set up some correspondence between the tasks which the planned changes are aimed at and possibility to solve some current or even strategy tasks of the enterprise. If the development potential of the enterprise does not meet the demands of its strategy tasks implementation, there will be the possibility that the tasks of change implementation process cannot be solved.

The systematization of the results of scientific researches allows to distinguish the following basic subsystems of the enterprise potential: financial, production, innovative, marketing, informational, management. We have defined some indexes inside each subsystem and the indexes show the specific character of each subsystem and the possibility of sustainable development strategy implementation.

The complex system of indexes reflecting enterprise potential for development is represented in Table 1.

Table 1. The enterprise potential subsystems and their indexes

\begin{tabular}{|l|l|l|l|}
\hline $\begin{array}{c}\text { Subsystems } \\
\text { of the } \\
\text { potential }\end{array}$ & Indexes & $\begin{array}{c}\text { The degree of each index } \\
\text { correspondence to strategy } \\
\text { development tasks }\end{array}$ & $\begin{array}{c}\text { The importance } \\
\text { weigh of each } \\
\text { index }\end{array}$ \\
\hline Finance & $\begin{array}{l}\text { The level of financial sustainability } \\
\text { Return on equity } \\
\text { Investing activity } \\
\text { Profitability } \\
\text { Sales volume }\end{array}$ & \\
\hline $\begin{array}{l}\text { Production } \\
\text { system }\end{array}$ & $\begin{array}{l}\text { The level of technical development } \\
\text { The level of technological development } \\
\text { Production infrastructure balance } \\
\text { The level of production assets modernization } \\
\text { The level of production assets capacity }\end{array}$ & & \\
\hline $\begin{array}{l}\text { Management } \\
\text { system }\end{array}$ & $\begin{array}{l}\text { Management system flexibility } \\
\text { The number of programs for staff development } \\
\text { The level of managerial processes organization }\end{array}$ & & \\
\hline
\end{tabular}




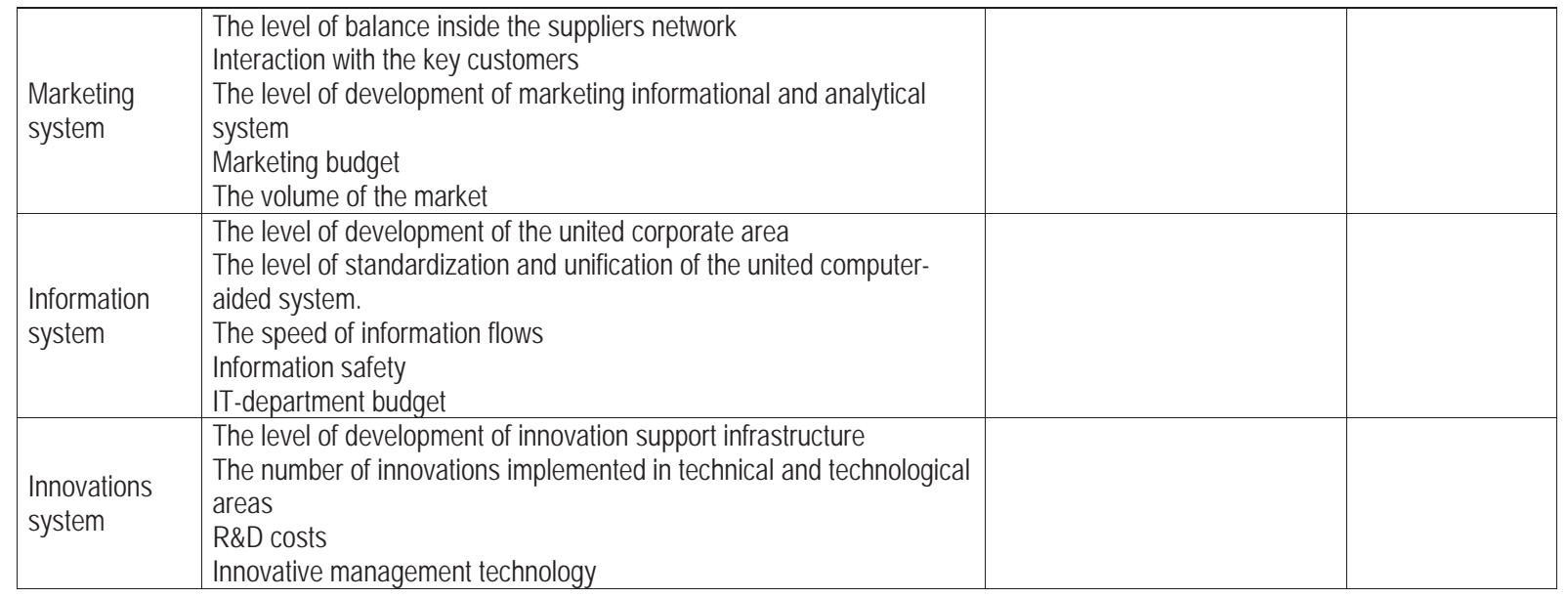

There is some difference between the indexes showing enterprise current state and the indexes of its development potential. Current state is assessed according to the current development data. Potential indexes show resources of the enterprise to achieve change strategy aims conveyed through the indexes. These indexes are also defined with the help of experts assessment method. Thus, potential assessment should be done in two stages with absolute indexes at the first stage and relative indexes at the second one. The authors of this research raised the problem of change necessity for the first time. We think that assessment of necessity of changes implementation is also one of the most important criterion. We are giving the following definition of necessity - a gap between the existing development potential level and its correspondence to the aims of change implementation. The more is the disparity the higher is the necessity to implement the changes. The assessment of change necessity is offered to be made on the basis of the indexes in Table 1. The value of the index from 'one' to 'five' will mean its correspondence to the aims of change implementation and its weigh will show its importance in the system of indexes showing the success of changes, so the higher will be the index the less necessary are the changes in this area.

\subsection{The enterprise assessment matrix}

The final stage of the complex substantiation of managerial decisions about changes implementation is the design of enterprise assessment matrix. The axes of the matrix are formed by the parameters of external environment comfort assessment, ability to implement the changes (staff resistance level), development potential level, level of changes implementation necessity. The matrix field is divided into nine squares characterizing possible differences in enterprise position. Rough management recommendations were given for strategy decisions elaboration concerning change implementation for each position of the enterprise on the matrix. The example of the matrix itself has been already given in some of our previous publications,so further we are going to give just the description of its fields.

The first zone "Essential Success" is characterized by the low level of staff resistance, the high level of external environment comfort, the high level of enterprise readiness to implement the changes and the high level of change necessity. This means that the enterprise has a great chance to implement the changes successfully. The most important here is to implement the changes quickly because the level of their necessity is high.

The second zone "Worthwhile but with preparations" has the high level of external environment comfort, average level of resistance and enterprise readiness, the necessity is high. When the enterprise is in this field it means that the possibility and urgency of changes is rather high but to implement them successfully the management should do some preliminary work to raise the enterprise potential and decrease the staff resistance.

The third zone "Low readiness" with high resistance level, low potential level, high environment comfort level and high change necessity means that any attempts to start the changes will fail. It is necessary to raise the readiness and decrease the staff resistance level.

The fourth zone "Success" has low level of staff resistance, high level of enterprise readiness to changes, average level of environment comfort, average level of change necessity.

The fifth zone "The Golden Mean" means that the company is practically ready to implement the changes which necessity degree is rather high. But the management should do great preliminary work with their staff as its resistance is not so low. 
The sixth zone "Not worthwhile in the nearest future" is characterized by high staff resistance level, low level of enterprise readiness, comfortable environment and average change necessity. Although there is some necessity in changes it is not sensible to implement them in the nearest period because they may be accompanied by significant staff resistance and low readiness level of the enterprise itself.

The seventh zone "Absence of necessity" has the low level of change necessity. Although staff resistance here is rather low and the enterprise readiness to changes is rather high the changes at this stage are not worthwhile because they are not necessary.

The eighth zone "Depression period" means that the changes are unnecessary but the high level of resistance in this zone and average level of company readiness to changes should force company management to make some decisions about company potential development and staff incentive programs.

The ninth zone "Crisis" is characterized by risky period in the enterprise to start the changes because of absence of necessity to implement major changes and crisis situation at the enterprise concerning its development potential and staff attitude.

\section{Discussions}

The assessment methodology of organization readiness, changes possibility and necessity was elaborated. This system is the basis of decision-making support while implementing organization changes in the industrial enterprise. Thus, suggested organizational instruments allow organizations to improve their readiness to changes, increase the degree of validity of managerial decisions at the stage of initial choice of further change implementation trends

Each group of factors influencing the successful implementation of organizational changes was analyzed from the point of view of the main procedures of changes implementation. Also the reasonability of practical use of the instruments of theoretical management schools indicated in the research work was grounded.

\section{Conclusion}

Nowadays the problem of development of strategic planning instruments is becoming more and more actual. The most usual decision which is made by management now is to rise efficiency in financial sphere and it has some effect but only for a short-term period. Long-term planning forces managers to work out more flexible aims and to formulate the tasks taking into account changeable external and internal conditions of environment. At the same time strong competition at the market forces the enterprises to optimize their strategy work by organizational changes introduction. The authors suggest using the elaborated assessment instruments to support the decision-making process in the situations of changes implementation to raise the validity of managerial decision-making.

\section{Acknowledgments}

The authors thank all participants of the study for their kind cooperation.

\section{References}

Porter M.E., (2004) Competitive advantage: creating and sustaining superior performance. New York: Free Press.

Harrington H.J., (2006) Change management excellence: the art of excelling in change management. Paton Press, pp:156.

Sokolova Y.A., (2013) The Board and stakeholders: interests and contradictions. The Matters of Economy Sciences,1, 21-25

Abrosimova E., Sedelnikov I., (2011) Stakeholders system analysis. The Journal of INZEKON, 3, 222-230

Weiner B.J., (2009) A Theory of Organization Readiness for Change. Implementation Science, 4 [Online] Available: http://www. implementationscience.com/content/4/1/67.

Khalitova I., (2013) Organization readiness to changes: the review of methodology and practical instruments of readiness evaluation. State Administration, 39, 152-162.

Liden F., (2011) Entrepreneurship and Economic Development (Studies in Development Economics and Policy) by Wim Naudé

Lindgren M. (2012) 21st Century Management: Leadership and Innovation in the Thought Economy. Palgrave Macmillan

Ansoff, I., Mcdonnell, E., (1990) Implanting Strategic Management, 2nd ed. Prentice Hall, pp: 520.

Hiatt, J., (2006). ADKAR:A model for change in business, government and our community. Prosci Research, pp:146 